\title{
O MEIO AMBIENTE COMO CONFORMAC̣ÃO CURRICULAR NA FORMAÇÃO DOCENTE
}

\author{
Jaiane de Moraes Boton* \\ Ronaldo Gonçalves de Andrade Costa** \\ Suzana Margarete Kurzmann*** \\ Eduardo A. Terrazzan****
}

RESUMO: O crescente apelo da Educação Ambiental como ferramentachave para a construção de sociedades sustentáveis e a sua institucionalização nos diversos níveis de ensino têm suscitado cada vez mais estudos a respeito da sua inserção no ensino superior, com a finalidade de preparar futuros professores para o desempenho do papel de orientador nessa tarefa, não reduzindo esse tema apenas ao ambiente físico e biológico, mas também às questões econômicas, sociais e culturais. Assim, neste trabalho, investigamos em que medida a temática Meio Ambiente está inserida na preparação de professores em formação na Universidade Federal de Santa Maria, sendo avaliados os Projetos Político-Pedagógicos dos Cursos de Licenciatura da referida Instituição de Ensino Superior.

Palavras-chave: Educação Ambiental; Meio Ambiente; Cursos de Licenciatura.

\section{THE ENVIRONMENT AS CONFORMATION IN TEACHER TRAINING CURRICULUM}

ABSTRACT: The growing demand for Environmental Education as a key tool in the creation of sustainable societies and their institutionalization at all levels of education has attracted more and more attention to studies on its insertion in High School (curriculum, epistemological, etc.), with the aim to prepare future teachers to perform the role of guide in this task, not only reducing this subject to the physical and biological environment, but also considering economic, social and cultural issues. Thus, in this study, we verified how much the subject "environment" is inserted in the training of teachers in the Universidade Federal de Santa Maria, Projects are assessed the Educational Policy of Undergraduate Courses of the Higher Education Institution.

Keywords: Environmental Education; Environment; Undergraduate Courses.
*Aluna do curso de Especialização em Gestão Educacional da Universidade Federal de Santa Maria (UFSM).

E-mail:

jaiambbio@gmail.com

* *Psicopedagogo e professor de ciências do ensino fundamental no Colégio Militar de Santa Maria (CMSM) E-mail:

ronaldogac@hotmail.com

*** Professora do Ensino

Médio da Escola Estadual

Manoel Ribas (Santa Maria/ RS), pesquisadora/colaboradora no Núcleo de Educação em

Ciências (NEC) do Centro de Educação (CE) da Universidade Federal de Santa Maria (UFSM) E-mail:

suzanakurzmann@yahoo.com.br *** * Professor associado da Universidade Federal de Santa Maria (UFSM), Coordenador responsável pelo Núcleo de

Educação em Ciências (NEC) do Centro de Educação (CE) da Universidade Federal de Santa Maria (UFSM). E-mail:

eduterrabr@yahoo.com.br 


\section{EDUCACุÃO AMBIENTAL NO SISTEMA EDUCACIONAL: ANTECEDENTES HISTÓRICOS E PANORAMA ATUAL}

A Educação Ambiental tem sido reconhecida mundialmente como estratégia para a construção de sociedades sustentáveis desde a Conferência sobre o Meio Ambiente Humano, promovida pela Organização das Nações Unidas (ONU), em 1972, na cidade de Estocolmo, capital da Suécia, evento conhecido como Conferência de Estocolmo, que foi pioneiro e decisivo para a consolidação da escalada ambientalista (CAVALARI, 2006). Em 1975, especialistas de 65 países reuniram-se e elaboraram um documento, a Carta de Belgrado, que preconizava uma nova ética planetária, recomendando, entre outros pontos, a criação de um Programa Mundial de Educação Ambiental.

Contudo, foi em 1977 que a Educação Ambiental se consolidou na Primeira Conferência Intergovernamental sobre Educação Ambiental, em Tbilisi, capital da República da Geórgia, pois foi o primeiro encontro mundial específico para tratar da Educação Ambiental, evento que ficou conhecido como Conferência de Tbilisi, e foi considerado importante por conceber o meio ambiente como inseparável dos aspectos econômicos, políticos e culturais, e também por recomendar que a Educação Ambiental fosse tratada de maneira interdisciplinar, inserindo-se como uma dimensão educativa nas disciplinas já existentes (CAVALARI, 2006), ou seja, como Tema Transversal.

A introdução formal da Educação Ambiental no Brasil se deu em 1973 com a criação da Secretaria Especial de Meio Ambiente (SEMA), vinculada ao Ministério do Interior, a qual estabeleceu como uma de suas atribuições "o esclarecimento e a educação do povo brasileiro para o uso adequado dos recursos naturais, tendo em vista a conservação do meio ambiente". Posteriormente, em 1981, foi instituída a Política Nacional de Meio Ambiente (Lei 6.938/81), que promoveu a inserção da Educação Ambiental em todos os níveis de ensino formal e não formal, visando a dar capilaridade ao tema no seio da sociedade brasileira.

Contudo, foi a Constituição Federal de 1988 que promoveu a mais significativa mudança ao atribuir ao poder público o dever de "promover a educação ambiental em todos os níveis de ensino e a conscientização pública para a preservação do meio ambiente" (Art. 225, $\int 1^{\circ}$, Inc. VI). Em termos gerais, a Educação Ambiental consolidou-se sob uma visão antropocêntrica, com a questão do utilitarismo dos recursos naturais sempre em evidência, e evoluiu mais recentemente para uma postura crítico-emancipatória.

Art $5^{\circ}$ - São objetivos fundamentais da educação ambiental:

I - o desenvolvimento de uma compreensão integrada do meio ambiente em suas múltiplas e complexas relações, envolvendo aspectos ecológicos, psicológicos, legais, políticos, sociais, econômicos, científicos, culturais e éticos (PNEA, Lei 9.795/99). 
No período de 1995 a 1998, o Ministério da Educação elaborou os Parâmetros Curriculares Nacionais (PCN), que, vinculados às Leis de Diretrizes e Bases (LDB/96), visam a estabelecer diretrizes para o currículo do Ensino Fundamental servindo como referência nacional para a prática educacional e ações políticas no âmbito da educação, além de reafirmar a responsabilidade do Estado com o Ensino Fundamental.

Neles os conteúdos a serem ensinados estão dispostos em dois grupos: Áreas Convencionais (Língua Portuguesa, História, Geografia, Matemática, Ciências Naturais, Arte, Educação Física e Língua Estrangeira); e os Temas Transversais (ética, educação ambiental, orientação sexual, pluralidade cultural e saúde) (FIGUEIRÓ, 2000). Entende-se como Tema Transversal o conjunto de valores, atitudes e comportamentos mais importantes que devem ser ensinados (GAVIDIA, 1996).

A transversalidade pretende que os temas integrem as áreas convencionais relacionando-as às questões da atualidade. Contudo, sabe-se que os programas de ensino das diferentes disciplinas estão estruturados curricularmente e sendo trabalhados de forma desarticulada das demandas da prática e da realidade encontradas nas escolas, caracterizando-se por concepções baseadas no modelo de racionalidade técnica (GHEDIN, 2008). Logo, a almejada transversalidade da temática ambiental, bem como dos demais temas transversais, deixa de ser uma vantajosa possibilidade de superação desse modelo de ensino arcaico para ser na verdade um obstáculo para sua implantação nos sistemas de ensino.

Em 1999, ocorreu a aprovação da Política Nacional de Educação Ambiental (PNEA), por meio da Lei n 9.795, de 27/04/1999, cujo art.10 diz que "a educação ambiental será desenvolvida como uma prática educativa integrada, contínua e permanente em todos os níveis e modalidades do ensino formal"; que "a educação ambiental não deve ser implantada como disciplina específica no currículo de ensino" e que "nos currículos de pós-graduação, extensão e nas áreas voltadas ao aspecto metodológico da educação ambiental, quando fizer necessário, é facultada a criação da disciplina específica".

Sobre essas determinações normativas, observa-se que, apesar de os PCN tratarem do Tema Transversal Meio Ambiente como apenas mais um entre os demais, a Educação Ambiental alçou status privilegiado, merecendo normativas específicas, as quais demandam um profissional docente devidamente habilitado, a fim de proporcionar uma eficaz capilarização da Educação Ambiental no sistema brasileiro de ensino. É necessário que, além do conhecimento da disciplina que irá ensinar, o docente domine minimamente o arcabouço teórico e didático pertinente à Educação Ambiental.

Nesse contexto, a Educação Ambiental avança nas universidades à medida que a complexidade da problemática ambiental vivida na atualidade impõe a necessidade de internalizá-la em seus currículos e práticas cotidianas de planejamento e gestão (GOMEZ, 2007), proporcionando uma ambientalização curricular das instituições como um todo, sobretudo nas públicas. 
De acordo com Oliveira (2007), a Ambientalização Curricular trata da transversalidade em três dimensões: (a) as disciplinas e grade curricular de cada curso; (b) as que incluem os aspectos de gestão ambiental institucional definida por sua política ambiental e (c) as que dizem respeito à dimensão da participação cidadã, que extrapola o âmbito das atividades institucionais, estando no nível das ações individuais ou de grupos dedicados às práticas sustentáveis, no próprio campus ou fora dele.

Nesse contexto, as instituições de Ensino Superior envolveram-se mais diretamente em prol de sua ambientalização em 1990 com a Declaração dos Líderes de Universidades para um Futuro Sustentável, que conta atualmente com 320 reitores e vice-reitores de todas as partes do mundo. Em 1998, a tendência à ambientalização consolidou-se com a declaração dos Princípios da Conferência Mundial sobre Educação Superior (Paris), que consubstancia como missão das Instituições de Ensino Superior (IES): educar, formar e pesquisar na Educação Superior com o compromisso de "contribuir para o desenvolvimento sustentável".

Em seguida, em 2000, a Unesco criou o Network for Reorienting Teacher Education a fim de implementar a Educação Ambiental no Ensino Superior de forma abrangente e eficaz. Esses esforços têm proporcionado um notório avanço da Educação Ambiental no Ensino Superior ibero-americano, sobretudo nos anos 1990, entretanto, ainda distante do sucesso esperado. Esse sucesso parcial, segundo Tassara (2007), deve-se ao fato de que não há como produzir uma verdadeira mudança na Educação Ambiental nas universidades sem que o seja através da intervenção radical sobre a articulação intrínseca entre as funções convencionais de ensino, pesquisa e extensão universitária.

Ao encontro disso, alguns autores (FERRARO JÚNIOR, 2004; VERDI \& PEREIRA, 2006; VIVEIRO \& CAMPOS, 2007) defendem a tese de que a inserção da temática ambiental no currículo não deve se restringir a momentos pontuais, mas deve perpassar todo o período de formação para que os futuros professores se "apropriem" dessas ideias e de fato tenham tempo para refletir, ganhar subsídios teóricos e práticos e acreditar na educação transformadora que poderão desenvolver em sala de aula com seus alunos e com toda a comunidade escolar.

\section{EDUCAC̣̃̃O AMBIENTAL NO CURRÍCULO ACADÊMICO: DISCIPLINA ESPECÍFICA OU TEMA TRANSVERSAL?}

No contexto curricular, Oliveira (2007, p. 450) esclarece que "não há políticas públicas explícitas e consolidadas para a formação ambiental em nível superior", sendo as escassas experiências existentes fruto de ação isolada e iniciativa exclusiva de docentes e pesquisadores da área.

Esse quadro é confirmado por alguns estudos sobre a Educação Ambiental nas IES, como no relato de Ferraro Júnior (2004), que demarca a falta 
de um processo de reflexão e modificação curricular no sentido da ambientalização da sua IES, a Universidade Estadual de Feira de Santana - BA. No estudo, o autor confirmou a tendência da associação da Educação Ambiental a disciplinas específicas, como, no caso, as disciplinas de Educação Ambiental (curso de Biologia) e Ciências do Ambiente (curso de Engenharia).

No mesmo sentido, Verdi e Pereira (2006) buscaram diagnosticar a incorporação da dimensão ambiental nos cursos de formação de educadores da Universidade Regional de Blumenau - Furb, como também, na pesquisa e extensão da instituição, e perceberam que existem várias inserções de temas ambientais nas atividades de ensino, pesquisa e extensão da Furb, porém isoladas, não oferecendo um aporte institucional suficiente para a formação de educadores ambientais nos Cursos de Licenciatura.

Avaliando a formação inicial de futuros professores de ciências de uma Instituição de Ensino Superior pública no interior de São Paulo, Viveiro e Campos (2007) constataram a reduzida inserção da temática ambiental no currículo e a utilização de obras referenciais que não contemplam as discussões mais recentes na área de Educação Ambiental. Diante disso lançam importantes questionamentos:

\footnotetext{
Por que um curso de formação de professores não tem maior preocupação com questões ambientais? Se não deve existir uma disciplina específica para abordar a Educação Ambiental, como garantir sua inserção dentro das disciplinas já existentes? Como os educadores que ministram aulas para os futuros professores entendem a importância da temática ambiental no currículo da Licenciatura? Além disso, estarão eles preparados para lidar com questões tão complexas que ultrapassem o discurso leigo acerca da temática ambiental? (p. 6, grifo nosso)
}

Dentre as questões acima propostas, uma é relevante para o entendimento da limitada abordagem curricular da Educação Ambiental nas universidades: trata-se da forma como essa Educação Ambiental deve ser implementada no currículo, se através de disciplina específica ou como Tema Transversal.

\section{A EDUCAÇÃO AMBIENTAL NA FORMAC̣ÃO DE PROFESSORES DA UFSM}

Este trabalho foi realizado junto ao Núcleo de Educação em Ciências (NEC) na Universidade Federal de Santa Maria (UFSM), no âmbito do Projeto Dilemas e Perspectivas para Inovação Educacional na Educação Básica e na Formação de Professores (Dipied), que visa a contribuir para uma melhor compreensão da organização das Estruturas Curriculares dos Cursos de Licenciatura de Instituições de Ensino Superior.

Desenvolvemos este trabalho a partir de uma pesquisa documental, contemplando materiais de diferentes naturezas. A concepção que adotamos referente ao termo documento vai ao encontro da de Chizzotti: 
[...] qualquer informação sob a forma de textos, imagens, sons, sinais, etc., contida em um suporte material (papel, madeira, tecido, pedra), fixada por técnicas especiais como impressão, gravação, pintura, incrustação, etc. Quaisquer informações orais (diálogo, exposição, aula, reportagens faladas) tornam-se documentos quando transcritos em suporte material (CHIZZOTTI, 2000, p. 109).

Para este autor, a pesquisa documental é parte integrante de qualquer pesquisa sistemática e precede ou acompanha os trabalhos de campo. Ela pode ser um aspecto dominante em trabalhos que visam a mostrar a situação atual de um determinado assunto ou que tentam traçar a evolução histórica de um problema.

No âmbito da pesquisa documental, encontra-se ainda a pesquisa bibliográfica, conforme Gil menciona, ou seja, "as fontes bibliográficas nada mais são do que documentos impressos por determinado público" (GIL, 1991, p. 51). Segundo esse autor, a pesquisa bibliográfica "é desenvolvida a partir de material já elaborado, constituído principalmente de livros e artigos científicos" (GIL, 1991, p. 48-49).

Utilizamos como fontes documentais a legislação referente à Educação Ambiental, os Projetos Político-Pedagógicos (PPP) dos Cursos de Licenciatura da Universidade Federal de Santa Maria, além de trabalhos e artigos acadêmico-científicos, para investigar em que medida a temática Meio Ambiente é empregada na preparação de professores para o tratamento de Temas Transversais na Educação Básica.

Para desenvolvermos essa pesquisa, traçamos o seguinte percurso: 1) Recolha de PPP; 2) Elaboração de um roteiro para coleta de informações; 3) Leitura dos PPP para coleta de informações, a partir de roteiro preestabelecido; 4) Organização e tratamento das informações coletadas; 5) Construção e interpretação dos resultados.

Cabe salientar que a presente pesquisa é um relato de conclusões de um estudo ainda em andamento, que se restringe a avaliar a Educação Ambiental como disciplina, desconsiderando a sua condução como Tema Transversal sobre Meio Ambiente, permeado nas demais disciplinas, tal como é preconizado nos Parâmetros Curriculares Nacionais (PCN, 1997).

No contexto da formação inicial, o presente estudo apresenta alguns resultados preliminares, mas relevantes para efeito de análise. Buscamos investigar a conformação curricular de Educação Ambiental concebida no currículo dos cursos de formação inicial de professores da Universidade Federal de Santa Maria. Para isso analisamos os Projetos Político-Pedagógicos dos Cursos de Licenciatura: Ciências Biológicas, Física, Química, Matemática, História, Geografia, Letras/Espanhol, Letras/Inglês, Letras/Português, Pedagogia/ Educação Infantil, Pedagogia/Séries Iniciais, Educação Especial, Educação Física, Música, Artes Visuais.

Nesses 15 cursos investigamos os PPP tendo em vista os seguintes itens: 
1. Objetivo do curso;

2. Perfil desejado do formando no curso;

3. Oferta de disciplina de Educação Ambiental na grade curricular.

Nesse contexto observamos que apenas o Curso de Licenciatura em Ciências Biológicas pontua a Educação Ambiental como um dos objetivos no momento em que evoca a necessidade de o formando "assumir o papel de educador, atuando na formação de cidadão, inclusive na perspectiva socioambiental". Além disso somente os cursos de Ciências Biológicas e Geografia demarcam a variável ambiental no perfil do licenciado, evocando de modo genérico a necessidade de uma consciência socioambiental na execução da atividade docente. Esses dois cursos oferecem a Disciplina Complementar de Graduação (DCG) em Educação Ambiental.

Notamos também que, no curso de Geografia, há a disciplina curricular obrigatória Gestão ambiental e conservação dos recursos naturais, porém, essa disciplina apresenta-se sob o enfoque antropológico dos recursos naturais utilizados pelo homem em seu proveito. Não há disciplina curricular regular em Educação Ambiental em nenhuma licenciatura da UFSM.

No âmbito da formação continuada de professores, as possibilidades de incorporação da dimensão da Educação Ambiental estão inseridas no mestrado em Educação ofertado pelo Centro de Educação (CE) e a especialização em Educação Ambiental ofertada pelo Centro de Ciências Rurais (CCR).

Sobre a especialização em Educação Ambiental, constata-se uma tendência à ecologização do tema (sensu LOUREIRO, 2004) e a existência de temas ligados ao meio rural ou atividades rurais, como o trabalho de Soares (2007), sobre representações da Educação Ambiental em alunos de uma escola rural.

Quanto ao mestrado em Educação do Centro de Educação, que é o curso de pós-graduação que tem linhas de pesquisa que possibilitam a abordagem do tema, analisamos dissertações produzidas entre 2006 e 2008 disponibilizadas no site do Programa de Pós-graduação em Educação da UFSM. Evidenciamos que, dos 95 trabalhos, apenas dois estão relacionados com a Educação Ambiental.

A inexistência de linhas de pesquisa e projetos no Centro de Educação em Educação Ambiental limita a difusão do tema no seio da formação continuada de professores da UFSM. Nesse sentido, observamos que as escassas pesquisas em Educação Ambiental aparecem como opções pessoais de seus autores, e não motivadas pela instituição.

A tendência de cunho utilitarista e preservacionista, tendo como discurso o desenvolvimento sustentável, concretiza-se no cotidiano da UFSM, considerando-se a falta de ambientalização da instituição no seu planejamento e gestão, vistas as constatações de que a questão ambiental não é adequadamente considerada, como atesta Santos (2008). 


\section{CONCLUSÃO}

A análise sobre a Educação Ambiental nos cursos de formação inicial e continuada de professores realizada na UFSM revelou este ser um tema precariamente abordado nos currículos, consoante com a realidade de diversas universidades em que a Educação Ambiental mais aparece como iniciativa pessoal de determinados professores, pondo em risco a meta da PNEA.

Percebemos que o campo da Educação Ambiental apresenta uma diversidade de abordagens práticas, principalmente nos relatos de experiência, que vão desde atividades de sensibilização até atividades reflexivas problematizadoras da realidade socioambiental na qual estamos imersos. Essa diversidade é ao mesmo tempo um desafio e um limite: um desafio, relacionado ao fato de se manter uma unicidade sobre o que venha a ser um trabalho de Educação Ambiental; e um limite, pois suscita a pergunta sobre que elementos são característicos aos trabalhos de Educação Ambiental, já que o campo é diverso e não restrito à comunidade científica. As reflexões sobre essa questão são apontadas em alguns dos trabalhos que caracterizam a Educação Ambiental primeiramente como uma prática educativa, devendo, assim, os seus trabalhos estarem vinculados a uma abordagem pedagógica. Entretanto esse posicionamento não é um consenso na comunidade científica.

No contexto da formação inicial de professores no âmbito da UFSM, o fato de a Educação Ambiental ser tratada como tema transversal e não como disciplina específica (exceto no caso da Geografia, como disciplina complementar, logo, não obrigatória) acaba deixando-a órfã no embate das disciplinas. O aluno, por sua vez, tende a priorizar a apropriação das disciplinas curricularmente estabelecidas, relegando a Educação Ambiental a um segundo plano.

Por fim, parece-nos que a ambientalização curricular pode ser uma solução alternativa e viável para o dilema entre disciplinarização e/ou transversalidade da Educação Ambiental, pois proporciona aos Cursos de Licenciatura uma estrutura adequada para formar o futuro docente capacitado a lidar com a educação ambiental nos moldes das normativas vigentes. 


\section{REFERÊNCIAS BIBLIOGRÁFICAS}

BARCELOS, V. Educação ambiental e antropologia: uma contribuição à formação de professores. Revista Brasileira de Educação Ambiental, Rio Grande, RS, n. 0, 2004.

BRASIL. Programa Nacional de Educação Ambiental - ProNEA. Ministério do Meio Ambiente, Diretoria de Educação Ambiental; Ministério da Educação, Coordenação Geral de Educação Ambiental. $3^{\text {a }}$ edição. Brasília/BR: Ministério do Meio Ambiente, 2005.

BRASIL. Constituição (1988). Constituição da República Federativa do Brasil, 1988. Brasília, DF: Senado Federal, Centro Gráfico, 1988.

BRASIL. Lei de Diretrizes e Bases da Educação Nacional (9.394/96). Brasília: MEC, 1996.

BRASIL. Lei no 6.938, de 31 de agosto de 1981. Dispõe sobre a Política Nacional do Meio Ambiente, seus fins e mecanismos de formulação e aplicação, e dá outras providências. Brasília, 1981.

BRASIL. Lei $n^{\circ}$ 9.795, de 27 de abril de 1999. Dispõe sobre a educação ambiental, institui a Política Nacional de Educação Ambiental e dá outras providências. Diário Oficial [da] República Federativa do Brasil. Brasília: DOU, 1999.

BRASIL. Parâmetros Curriculares Nacionais: meio ambiente, saúde. Brasília: MEC/SEF, 1997.

CAVALARI, Rosa Maria Feiteiro. Educação Ambiental, políticas públicas e contexto escolar. In: BARBOSA, Raquel Lazzari Leite (org.). Formação de Educadores: artes e técnicas, ciências políticas. São Paulo: Unesp, 2006, p. 353-366.

FERRARO-JÚNIOR, L. A. "A universidade e a formação do educador ambiental: uma breve reflexão sobre as experiências da Universidade Estadual de Feira de Santana - UEFS". Revista Brasileira de Educação Ambiental, Feira de Santana, n. 1, 2004.

FIGUEIRÓ, Mary Neide Damico. "A viabilidades dos Temas Transversais à luz da questão do trabalho docente". Revista Psicologia Social e Institucional, Londrina, v. 2, n. 1, jun. 2000. Disponível em: <http://www2.uel.br/ccn/psicologia/revista/textov2n12.htm>. Acesso em: 1 ago. 2008.

GARCÍA, Carlos Marcelo. Formação de professores: para uma mudança educativa. Porto/PT: Porto, 1999, p. 271.

GAVIDIA, Valentín. A construção do conceito transversalidade. In: ÁLVAREZ, Maria Nieves, et al. Valores e temas transversais no currículo. Porto Alegre: Artmed, 2002, p. 15-30.

GHEDIN, Evandro; ALMEIDA, Maria Isabel de \& LEITE, Yoshie Ussami Ferrari. Formação de professores: caminhos e descaminhos da prática. Brasília: Líber Livro, 2008, p. 142.

GÓMEZ, J. A. C. La educación ambiental em las universidades y la enseñanza superior: viejas e nuevas perspectivas para la acción em clave de futuro. In: Congresso Ibero-americano de Educação Ambiental, 5, 2006 Joinville, SC, Brasil. Anais... Joinville: Catalisa, 2006.

GUIMARÃES, M. Educação Ambiental Crítica. In: LAYRARGUES, P. P. (coord.). Identidades da educação ambiental brasileira. Brasília: Ministério do Meio Ambiente, 2004.

LOUREIRO, Carlos Frederico B. Trajetória e fundamentos da educação ambiental. São Paulo: Cortez, 2004.

MACEDO, E. F. Parâmetros Curriculares Nacionais: a falácia de seus temas transversais. In: MOREIRA, A.F. (org.). Currículo: políticas e práticas. Campinas: Papirus, 1999.

OLIVEIRA, Haydée Torres. O processo de ambientalização curricular na Universidade Federal de São Carlos nos contextos de ensino, pesquisa, extensão e gestão ambiental. In: Congresso Ibero-americano de Educação Ambiental, 5, Joinville, SC, Brasil.

SANTOS, E. C. R. A questão dos resíduos sólidos na Casa do Estudante Universitário, Restaurante Universitário e Reitoria da Universidade Federal de Santa Maria. In: Fórum Mundial de Educação Santa Maria, 2008.

SANTOS, L. M. S. \& MARTINS, I. Mapeamento do campo a partir de publicações em periódicos das áreas de educação ambiental, educação em ciências e educação no período de 1999 a 2006. In: Encontro Nacional Pesquisa em Educação em Ciências (Enpec), 6, 2007. Resumos. Florianópolis: UFSC, 2007.

SOARES, N. B. Educação ambiental no meio rural: estudo das práticas ambientais da escola Dario Vitorino Chagas - comunidade rural do Umbu - Cacequi/RS. Monografia (especialização). Universidade Federal Santa Maria (UFSM), Santa Maria, RS, 2007. 
SORRENTINO, Marcos \& TRAJBER, Rachel (org.). Perspectivas da Educaşão Ambiental na região ibero-americana. Rio de Janeiro: Associação Projeto Roda Viva, 2007.

TASSARA, E. T. O. "Educação ambiental e universidade: ensino, pesquisa e extensão". In: Perspectivas da educação ambiental na região ibero-americana: conferências. Congresso Ibero-americano de Educação Ambiental, 5, 2007. Rio de Janeiro: Associação projeto Roda Viva, 2007.

VERDI, M. \& PEREIRA, G. R. A educação ambiental na formação de educadores: o caso da universidade regional de Blumenau - Furb. Revista Furb, Blumenau, SC, n. 17. julho a dezembro de 2006.

VIVEIRO, A. A. \& CAMPOS, L. M. L. Inserção da temática ambiental no currículo de um curso de formação de professores de ciências: panorama inicial a partir da análise das ementas. In: VI Enpec. Resumos. Florianópolis, 2007.

ARAÚJO, L. M. M. Formação docente, educação ambiental e representações sociais: uma pesquisa com três professores(as) especialistas em educação ambiental. 2007. Dissertação (mestrado) - Universidade Federal Santa Maria (UFSM), Santa Maria, RS, 2007. 